\title{
Depressive disorders and comorbidities among the elderly: a population-based study
}

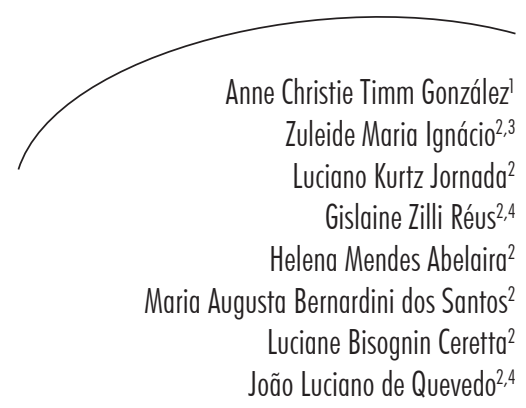

\section{Abstract}

Objective: The present study assessed the prevalence of depressive disorders and associated factors in a sample of elderly persons in the south of Santa Catarina. Methods: A crosssectional study based on population data was performed, evaluating 1021 elderly individuals aged between 60 and 79 years. Home interviews were carried out using the Portuguese version of the Mini International Neuropsychiatric Interview (MINI), in order to collect demographic data, information on hypertension and reports of acute myocardial infarction. The disorders studied were current depressive episode, dysthymia and a comorbidity of a depressive episode and dysthymia, representing double depression. The comparison of mean age and prevalence was made with the t-test and other associations were analyzed using the Chi-squared test. Results: The prevalence of depression was $26.2 \%$, while $5.5 \%$ of the sample suffered from dysthymia and $2.7 \%$ experienced double depression. Risk factors for depression were: nine or more years of schooling [PR $=1.44$ (1.17 to 1.77$)$; $\mathrm{p}<0.05$ ] and being a current smoker [OR $=1.63(1.30-2.05) ; \mathrm{p}<0.05]$. Dysthymia was associated with the male gender $[\mathrm{OR}=6.46$ (3.29 to 12.64$) ; \mathrm{p}<0.05]$, reports of hypertension $[\mathrm{OR}=$ 2.55 (1.53 to 4.24); $\mathrm{p}<0.05$ ] and being either a current [OR $=1.86(1.02$ to 3.42$) ; \mathrm{p}<0.05]$ or past or former [OR $=2.89$ (1.48 to 5.65); $\mathrm{p}<0.05]$ smoker. The same risk factors as for dysthymia were found for double depression: male [OR $=4.21$ (1.80 to 9.81); $\mathrm{p}<0.05$ ], reports of hypertension [OR $=8.11$ (3.32 to 19.80); $\mathrm{p}<0.05]$, and being either a current $[\mathrm{OR}=5.72$ (1.64 to 19.93); $\mathrm{p}<0.05]$ or past $[\mathrm{PR}=13.11$ (3.75 to 45.86); $\mathrm{p}<0.05]$ smoker. Conclusions: The present study shows that depressive disorders are a common phenomenon among the elderly. The results not only corroborated with other studies, but found slightly higher levels of depressive disorders among the elderly population.

\footnotetext{
Universidade do Sul de Santa Catarina, Curso de Medicina. Tubarão, SC, Brasil.

2 Universidade do Extremo Sul Catarinense, Unidade Acadêmica de Ciências da Saúde, Programa de Pósgraduação em Ciências da Saúde, Laboratório de Neurociências. Criciúma, SC, Brasil.

3 Universidade Federal da Fronteira Sul, Laboratório de Fisiologia, Farmacologia, Patologia e Psicopatologia. Chapecó, SC, Brasil.

4 The University of Texas, Health Science Center, Medical School, Center for Translational Psychiatry, Department of Psychiatry and Behavioral Sciences. Houston, Texas, USA.
}

Key words: Elderly; Depressive Disorder; Prevalence; Comorbidity. 


\section{INTRODUCTION}

According to the World Health Organization (WHO) depression occupied first place in the rank of major diseases that cause most nonfatal disabilities and third place in the global burden of disability in 2004. It is estimated that by 2030 the condition will have the highest global burden among diseases. ${ }^{1}$

Depression is one of the most common psychiatric disorders among the elderly. ${ }^{2}$ It is a disabling pathological condition that is hugely damaging to the functional and social lives of individuals. ${ }^{3}$ In addition to the serious damage to which the patient is subjected during a depressive state, the condition is chronic and recurrent, ${ }^{4}$ which predisposes people to a constant state of worry and negative expectations, thus necessitating treatment in tertiary care services. ${ }^{5}$

Depression may also be associated with chronic physical illnesses and other psychiatric disorders, a pattern which is heightened in elderly individuals. ${ }^{6}$ Increased population aging has resulted in an increase in morbidity, and also brings greater numbers of silent chronic diseases, which can be crippling for elderly persons and result in a significant increase in the cost of health care. ${ }^{7}$

Studies show that somatic diseases accompanied by psychiatric disorders in a significant portion of patients treated in primary care can mask psychiatric symptoms and impair diagnosis. ${ }^{8}$ Among the elderly, the masking of depression may be even more prominent, given that chronic somatic diseases are more frequent and consequent complaints more exacerbated, in turn rendering symptoms of depression less apparent. ${ }^{9}$ Moreover, the symptoms caused by depression among the elderly are more somatic than symptoms in younger people, a feature that can impair diagnosis of the disorder. ${ }^{10}$ It is also important to note that comorbidities of depression and other chronic somatic diseases further increase the harmful effects upon health, ${ }^{11}$ thus heightening levels of suffering, as well as economic and social costs.
Along with other psychiatric comorbidities, depression is often accompanied by a dysthymic disorder, ${ }^{12,13}$ which, in most cases begins in childhood or adolescence, becoming less common in middle and old-age. ${ }^{12}$ Although less frequent, dysthymia in older people brings with it greater social impairment, such as fewer relationships with family and friends, problems at work or in other social environments, and participation in fewer pleasurable or social activities. ${ }^{14}$

Although it is a disorder that occurs frequently in the population, both in primary care and in psychiatry, it is difficult to detect. ${ }^{15}$ One of the factors that make the diagnosis of dysthymia difficult is the high frequency of psychiatric comorbidities. ${ }^{16}$

A comorbidity of dysthymia and depression is referred to as double depression (DD), where acute depression overrides the chronic framework of dysthymia. ${ }^{5} \mathrm{DD}$ is characterized by high levels of depressive symptoms and greater social prejudice among the general population. ${ }^{17}$ Among the elderly, DD is responsible for a greater sense of hopelessness than either depression or dysthymia on its own. ${ }^{18}$

The increase in population aging is already an established fact, both in terms of actual and forecasted numbers for the next 50 years, according to studies published by the WHO. ${ }^{19,20}$ This data, along with the findings that depression occupies first place among the most disabling and most globally burdening diseases, and moreover tends to rank among the most incapacitating diseases, ${ }^{1}$ are important factors that have boosted research into the clinical identification of the condition, as well as other variables inherent to the elderly, which can contribute to more appropriate and effective treatment to improve the quality of life of the population.

Therefore, the aim of this study was to assess the prevalence of depressive disorders and their association with sociocultural factors and somatic comorbidities among the elderly in the south of Santa Catarina. 
METHOD

A cross-sectional study, based on population data was performed. The study was part of a pilot project entitled "Criciúma Diabetes Coorte (Criciúma Diabetes Cohort Study) (CDC)", surveying the population of the municipality of Criciúma in the state of Santa Catarina. The pilot project consists of two population samples. One of these is made up of patients with type II diabetes, while the other studied a strata of the general population, homogeneously distributed across the various regions of the municipality.

A total of 1,021 elderly individuals were evaluated, aged between 60 and 79 years old, taken from a sample of the general population without diabetes (non-clinical sample). In order to avoid possible bias due to the difficulties of testing very old people, individuals older than 80 years were not included in the survey. Data relating to patients with diabetes was analyzed using a different type of design and formed part of another study of the group being researched. ${ }^{21}$

The sample size was calculated by the convenience method, however, considering that in the IBGE Census of $2010^{22}$ the population in the municipality of individuals in the age range of the study was 14,090 , a sampling error of approximately $3 \%$ was considered.

Data collection was based on the previously mentioned database. Data was collected through household interviews conducted by health workers trained for the purpose between March and November 2010. The following sociodemographic characteristics were evaluated: age, gender, marital status and education. Additionally, reports of hypertension $(\mathrm{SAH})$, acute myocardial infarction (AMI) and smoking habits were also analyzed. The assessed psychiatric disorders were: depressive episodes (depression), dysthymia and double depression (DD).

The psychiatric diagnoses were obtained from a structured interview using the Portuguese version of the Mini International Neuro Psychiatric Interview $(\mathrm{MINI})^{23}$. The interview was standardized and performed according to DSM-IV (APA) and ICD10 criteria (WHO). This can be quickly applied by trained professionals (in around 15 minutes) and can be used in clinical practice and research after a short training session (one to three hours). ${ }^{23}$

Data was tabulated and analyzed using the Statistical Package for Social Sciences (SPSS) version 20.0. The descriptive results are presented as prevalence and prevalence ratios, except for age, which was the only variable analyzed quantitatively, and is represented by its mean and standard deviation. Comparisons between mean ages were made using the Student's t-test. The results are expressed as the test value ( $t$ ), its degrees of freedom (df) and $p$ values when significant or NS when not significant. As there is an overlap between variables presented in a dichotomous manner, the study of the associations between depressive disorders and other demographic and clinical social variables was analyzed using Pearson's chi-squared test or the Fisher exact test, as appropriate, and described the prevalence ratio with respective intervals of confidence. A bilateral significance level of 95\% was adopted in all the tests.

This study was approved by the Ethics Research Committee of the Universidade do Extremo Sul Catarinense (UNESC), under registration number 310/2009. After the introduction and identification of the researcher, each volunteer received information about the procedures and signed a Free and Informed Consent Form. All survey participants who were psychiatrically diagnosed in the interview were referred to their respective medical care professionals or, in their absence, referred for medical evaluation.

\section{RESULTS}

The 1,021 individuals in the sample had an average age of $67.3( \pm 4.8)$ years. Table 1 shows the sociodemographic data of the participants, with respect to age, gender, relationship status and education. 
Table 1. Distribution of sociodemographic data of 1,021 elderly persons residing in the community. Criciúma, SC, 2010.

\begin{tabular}{|c|c|c|}
\hline Variable & Factor & Result \\
\hline Age & $\begin{array}{c}\text { Mean } \\
\text { Standard deviation }\end{array}$ & $\begin{array}{l}67.3 \text { years } \\
4.8 \text { years }\end{array}$ \\
\hline Gender & $\begin{array}{l}\text { Male } \\
\text { Female }\end{array}$ & $\begin{array}{l}425(41.6 \%) \\
596(58.4 \%)\end{array}$ \\
\hline Marital status & $\begin{array}{l}\text { With partner } \\
\text { Without partner }\end{array}$ & $\begin{array}{l}561(54.9 \%) \\
460(45.1 \%)\end{array}$ \\
\hline Educational level & $\begin{array}{l}\text { Up to eight years } \\
\text { Nine years or more }\end{array}$ & $\begin{array}{l}575(56.3 \%) \\
476(43.7 \%)\end{array}$ \\
\hline
\end{tabular}

Table 2 shows the self-reported data on hypertension, myocardial infarction and smoking habits. The following prevalence rates were found: 318 individuals (31.1\%) had hypertension; 136 individuals $(13.2 \%)$ had a history of AMI and 526 individuals $(51.5 \%)$ said they were smokers or former smokers.
Figure 1 shows the prevalence of cases of depression and dysthymia and the two disorders in combination (DD). Approximately one quarter of the study population $(26.2 \%)$ had scores characterizing depression, $5.5 \%$ were characterized with dysthymia; and $2.7 \%$ had DD.

Table 2. Distribution of clinical aspects of 1,021 elderly persons living in the community. Criciúma, SC, 2010.

\begin{tabular}{|c|c|c|}
\hline Variable & Factor & Result \\
\hline $\mathrm{SAH}$ & $\begin{array}{l}\text { Present } \\
\text { Absent }\end{array}$ & $\begin{array}{l}318(31.1 \%) \\
703(68.9 \%)\end{array}$ \\
\hline AMI & $\begin{array}{l}\text { Present } \\
\text { Absent }\end{array}$ & $\begin{array}{l}136(13.2 \%) \\
886(86.8 \%)\end{array}$ \\
\hline Smoking & $\begin{array}{l}\text { Current smoker } \\
\text { Ex-smoker } \\
\text { Never smoked }\end{array}$ & $\begin{array}{l}375(36.7 \%) \\
151(14.8 \%) \\
495(48.5 \%)\end{array}$ \\
\hline
\end{tabular}

$\mathrm{SAH}=$ systemic arterial hypertension; $\mathrm{AMI}=$ acute myocardial infarction. 


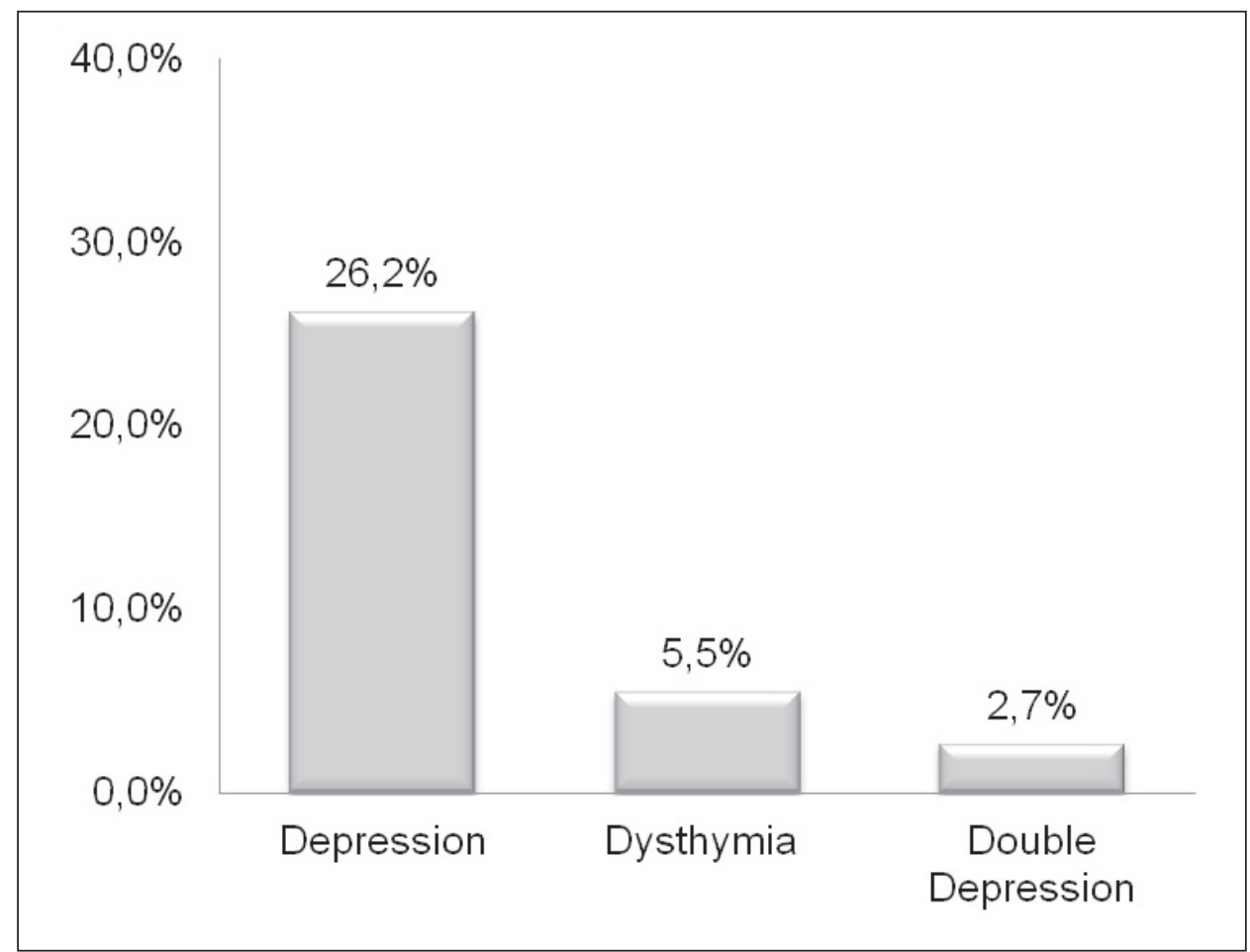

Figure 1. Distribution of prevalence of depressive disturbances among 1,021 elderly persons in the community. Criciúma, SC, 2010.

There were no significant differences in the development of depressive disorders compared with mean age. Individuals with depression, according to the scores studied, had a mean age of 67.4 years, while those classified with negative scores for depression had a mean age of 67.27 $(\mathrm{t}=0.38, \mathrm{df}=408.13 ; p=\mathrm{NS})$. The same comparison for dysthymia found mean ages of 63.39 and 63.30 years, respectively $(\mathrm{t}=0.14, \mathrm{df}=1019, p=\mathrm{NS})$. For a comorbidity of depression and dysthymia, the results were, respectively, 67.18 years versus 67.31 years $(\mathrm{t}=0.14, \mathrm{df}=1019, \mathrm{p}=\mathrm{NS})$.

Table 3 shows the associations between the quantitative and sociobiological variables and the presence of depression. The risk factors for depression were: nine years or more of study $\left(\chi^{2}=12.24 ; \mathrm{df}=1 ; p<0.001\right)$ and current smoker $\left(\chi^{2}=18.55 ; \mathrm{df}=1 ; p<0.001\right)$. Dysthymia was positively associated with the male gender $\left(\chi^{2}=40.01 ; \mathrm{df}=1 ; p<0.001\right)$, reports of hypertension $\left(\chi^{2}=13.89 ; \mathrm{df}=1 ; p<0.001\right)$ and being both a current $\left(\chi^{2}=4.18 ; \mathrm{df}=1 ; p=0.041\right)$, and past or former smoker $\left(\chi^{2}=10.38 ; \mathrm{df}=1\right.$; $p=0.001)$. In terms of DD, the same risk factors were repeated for dysthymia: male $\left(\chi^{2}=13.20\right.$; $\mathrm{df}=1 ; p<0.001)$, reports of hypertension $\left(\chi^{2}=30.19 ; \mathrm{df}=1 ; p<0.001\right)$, and being a current $\left(\chi^{2}=9.67 ; \mathrm{df}=1 ; p=0.002\right)$ and former smoker $\left(\chi^{2}=27.49 ; \mathrm{df}=1 ; p<0.001\right)$. 
Table 3. Association between sociodemographic and clinical variables and depressive disturbances in 1,021 elderly persons in the community. Criciúma, SC, 2010.

\begin{tabular}{lccc}
\hline Factor & $\begin{array}{c}\text { Depressive episode } \\
\text { PR (CI 95\%) }\end{array}$ & $\begin{array}{c}\text { Dysthymia } \\
\text { PR (CI 95\%) }\end{array}$ & $\begin{array}{c}\text { Double depression } \\
\text { PR (CI 95\%) }\end{array}$ \\
\hline Gender & 1.03 & $\mathbf{6 . 4 6}$ & 4.21 \\
(Male/female) & $(0.84-1.27)$ & $(3.29-12.64)^{*}$ & $(1.80-9.81)^{*}$ \\
Marital status & 1.17 & 0.95 & $\mathbf{0 . 7 1}$ \\
(With/without partner) & $(0.95-1.44)$ & $(0.57-1.58)$ & $(0.34-1.48)$ \\
Educational level & 1.44 & 1.04 & $\mathbf{0 . 9 7}$ \\
(9 years or more/up to 8 years) & $(1.17-1.77)^{*}$ & $(0.63-1.74)$ & $(0.46-2.02)$ \\
SAH & 1.00 & 2.55 & 8.11 \\
(Yes/no) & $(0.80-1.25)$ & $(1.53-4.24) *$ & $(3.32-19.80)^{*}$ \\
AMI & 0.86 & 1.60 & 1.43 \\
(Yes/no) & $(0.62-1.20)$ & $(0.85-3.02)$ & $(0.55-3.69)$ \\
Smoking & 1.63 & 1.86 & $\mathbf{5 . 7 2}$ \\
(Current/never smoked) & $(1.30-2.05) *$ & $(1.02-3.42)^{*}$ & $(1.64-19.93)^{*}$ \\
(Ex-smoker/never smoked) & 1.33 & 2.89 & 13.11 \\
& $(0.97-12.82)$ & $(1.48-5.65)^{*}$ & $(3.75-45.86) *$ \\
\hline
\end{tabular}

$\mathrm{PR}=$ prevalence ratio; $\mathrm{CI}=$ confidence interval; ${ }^{p} p<0.05$ logistical regression; $\mathrm{SAH}=$ systemic arterial hypertension; AMI= acute myocardial infarction.

\section{DISCUSSION}

The data extracted in this study revealed a prevalence of depression of $26.2 \%$ in the elderly population aged between 60 and 79 years. The prevalence of depression in the general population can range from 11 to $18.4 \%,{ }^{24}$ and can reach $23 \%,{ }^{25}$ among people who have another chronic disease, and $23.9 \%,{ }^{26}$ in patients treated in primary health care. Among the elderly, the prevalence of depression reaches approximately $20 \%$ among noninstitutionalized people. ${ }^{27} \mathrm{In}$ a systematic review, ${ }^{28}$ it was observed that the frequency of depression in elderly patients varies greatly between different populations, but can include about $40 \%$ of elderly individuals in some populations. These results support those of the present study, confirming that the prevalence of depression is high in older people. While chronic somatic diseases are more common among the elderly, ${ }^{9}$ and depression is a disorder that predisposes individuals to greater health risks and a higher severity of somatic diseases, ${ }^{11}$ the results of this and other studies ${ }^{9,11}$ warn of the fact that depression should be taken into account not only during medical examinations, but also during the treatment of the elderly.

In terms of education, studies have found that a limited education was one of the factors associated with depression. ${ }^{29}$ However, in a systematic review, the authors found differences between the findings. ${ }^{30}$ Whilst some studies found a positive association, others found no correlation between levels of education and depression. This study found higher depression scores in individuals with higher levels of education. Importantly, studies often consider different factors that may be inherent in their results. For example, one factor that is consistency associated with depression is being female and older. ${ }^{29,30}$ These factors were not stratified in this study in order to assess whether they could be related to level of education. Other more detailed studies are needed to be able to analyze which specific characteristics of the 
population studied in this study may be related to education level and depression.

In addition to depression, the present study evaluated the prevalence of dysthymia, a disorder which can present itself separately and quite often in comorbidity with depression. ${ }^{12,13,15} \mathrm{It}$ is estimated that the prevalence of dysthymia during life is between $3.1 \%$ and $6.4 \% .{ }^{31}$ Among the elderly, dysthymia affects $2 \%$ to $6 \%$ of population. ${ }^{32-34}$ In the present study, the prevalence of dysthymia found was $5.5 \%$, indicating that the condition presents itself with significant frequency in older adults in this region and that it is consistent with percentages found in studies of other regions. ${ }^{32}$

With regard to the other factors associated with a higher prevalence of dysthymia, which were the male gender, a history of smoking and the presence of hypertension, the results of the present study corroborate other studies..$^{35}$ Some authors suggest that smoking is strongly associated with depression, dysthymia and the impaired quality of life of patients with cardiac diseases. ${ }^{36}$ Therefore, this data suggests that smoking may be an important factor inherent in hypertension as well as affective disorders among the elderly investigated by this research.

Studies suggest that $39 \%$ to $68 \%$ of those classed as dysthymic develop DD. ${ }^{37}$ This study was cross-sectional, and did not follow the evolution of the condition of patients. It did, however, find a prevalence of $2.7 \%$ of elderly individuals with DD. Although not the focus of this study, it is important to note that DD has been identified as a condition that predisposes patients to greater psychosocial harm as well as heightened suffering and an increased risk of suicide. ${ }^{38,39}$

In identifying a high prevalence of depression, dysthymia and DD in an elderly population, this study highlights the importance of more systematic evaluations, both in primary health care and scientific research, aimed principally at observing specific features related to the symptoms and comorbidities of the age groups studied, as other studies have highlighted. ${ }^{40}$
Importantly, the significant occurrence of depression in the study population may be associated with a lack of correct diagnoses and treatment of depressive disorders. An underlying factor relevant to the lack of diagnosis may well be the difficulty in assessing subjective data of mental disorders, thus significantly reducing the effectiveness of diagnosis and treatment. ${ }^{41}$ While the symptoms of the elderly and young adults may be similar, in the elderly, the reporting of somatic symptoms, such as changes in sleep patterns and a lack of appetite, is more intense than psychological symptoms, and these individuals suffer more from anhedonia than sadness and cognitive losses. ${ }^{42}$ In addition, older people often experience chronic diseases that are associated with depression, leading to a reduction in the adherence to treatment, negligence in self-care, poorer quality of life, increased seeking of health services, higher morbidity and mortality, and risk of suicide. ${ }^{43,44}$

Despite being a relevant and comprehensive research of a section of the local municipal population, this study was based around a nonclinical sample. Thus, it has the important feature of collecting data from the elderly population in general. However, it has the limitation of not having accessed the specific clinical data of patients in psychiatric treatment. Another limitation was the failure to classify the elderly into more advanced and less advanced ages, as well as non-consideration of other social and environmental factors that may be linked to a higher risk and greater severity of symptoms of depressive disorders. ${ }^{28,29}$

\section{CONCLUSION}

The data shows that cases of depression are common phenomena among elderly people from within the general population. As well as corroborating the results of other surveys, the sample of the present study revealed that the signs of depressive disorders were slightly more prevalent in the studied population. The results also showed associations between socio-environmental factors 
and chronic somatic diseases and depressive disorders, for example, depression and educational level, as well as identifying an association between smoking and hypertension. These findings have been highlighted in other studies and are deserving of further research. Apparently conflicting results, such as the positive correlation with higher levels of education, should be targeted by future research, in order to correlate factors that may be present in the specific studied population.

\section{REFERENCES}

1. Word Health Organization. The Global Burden of Disease: 2004 Update. Geneva: World Health Organization; 2008.

2. Word Health Organization (2001). A Call for Action by World Health Ministers. 54th World Health Assembly: Mental Health. Geneva: World Health Organization; 2001.

3. Ormel J, Vonkorff M, Van Den Brink W, Katon W, Bilman E, Oldehinkle T. Depression, anxiety, and social disability show synchrony of change in primary care patients. Am J Public Health 1993;83(3):385-90.

4. Mueller TI, Leon AC, Keller MB, Solomon DA, Endicott J, Coryell W, et al. Recurrence after recovery from major depressive disorder during 15 years of observational follow-up. Am J Psychiatr 1999;156(7):1000-6.

5. Tavares RV, Juruena MF. Depressão dupla refratária: um exemplo de transtorno afetivo recorrente. Am J Psychiatr 1999;156(7):1000-6.

6. Duarte MB, Rego MA. Depression and clinical illness: comorbidity in a geriatric outpatient clinic. Cad Saúde Pública 2007;23:691-700.

7. Alves LC, Leite IC, Machado CJ. Health profile of the elderly in Brazil: analysis of the 2003 National Household Sample Survey using the Grade of Membership method. Cad Saúde Pública 2008;24(3):535-46.

8. Skapinakis P, Araya R. Common somatic symptoms, causal attributions of somatic symptoms and psychiatric morbidity in a cross-sectional community study in Santiago, Chile. BMC Res Notes 2011;26(4):1-5.

9. Samuels SC, Brickman AM, Burd JA, Purohit DP, Qureshi PQ, Serby M. Depression in autopsyconfirmed dementia with Lewy bodies and Alzheimer's disease. Mt Sinai J Med 2004;71(1):55-62.

\section{AKNOWLEDGEMENTS}

This study was partly supported by grants from the Conselho Nacional de Desenvolvimento Científico e Tecnológico (the National Scientific and Technological Development Council) (CNPq) (João Quevedo and Gislaine Z. Réus), the Instituto Cérebro e Mente (the Brain and Mind Institute) and the Universidade do Extremo Sul Catarinense (João Quevedo).

10. Hegeman JM, Kok RM, Van der Mast RC, Giltay EJ. Phenomenology of depression in older compared with younger adults: meta-analysis. Br J Psychiatr 2012;200(4):275-81.

11. Moussavi S, Chatterji S, Verdes E, Tandon A, Patel V, Ustun B. Depression, chronic diseases, and decrements in health: results from the World Health Surveys. Lancet 2007;370;(9590):851-8

12. Rhebergen D, Graham R, Hadzi-Pavlovic D, Stek M, Friend P, Barrett M, et al. The categorisation of dysthymic disorder: can its constituents be meaningfully apportioned? J Affect Disord 2012;143(1-3):179-86.

13. Sansone RA, Correll T. Dysthymic disorder: the persistent depression. Psychiatry 2005;9:1-12.

14. Pahkala K, Kivelä SL, Laippala P. Social and environmental factors and dysthymic disorder In old age. J Clin Epidemiol 1992;45(7):775-83.

15. Sansone RA, Sansone LA. Dysthymic disorder: forlorn and overlooked? Psychiatry 2009;6(5):46-50.

16. Autonell J, Vila F, Pinto-Meza A, Vilagut G, Codony M, Almansa J, et al. One year prevalence of mental disorders comorbidity and associated sociodemographic risk factors in the general population of Spain. Results of the ESEMeD-Spain study. Actas Esp Psiquiatr 2007;35:4-11.

17. Keller MB, Shapiro RW. "Double depression": superimposition of acute depressive episodes on chronic depressive disorders. Am J Psychiatr 1982; 139(4):438-42.

18. Klein DN, Shankman SA, Rose S. Dysthymic disorder and double depression: prediction of 10-year course trajectories and outcomes. J Psychiatr Res 2008;42(5):408-15.

19. World Health Organization. Active ageing: a policy framework. Geneva: WHO; 2002. 
20. World Health Organization. World health statistics 2010. Geneva: World Health Organization; 2010.

21. Ceretta LB, Réus GZ, Abelaira HM, Jornada LK, Schwalm MT, Hoepers NJ, et al. Increased prevalence of mood disorders and suicidal ideation in type 2 diabetic patients. Acta Diabetol 2012;49(1):227-34.

22. Intituto Brasileiro de Geografia e Estatística. Censo 2010. Rio de Janeiro: IBGE; 2010 [acesso em 12 ago. 2014]. Disponível em: http://cidades.ibge.gov.br/ xtras/perfil.php?codmun $=42046$

23. Amorim P. Mini International Neropsychiatric Interview (MINI): validação de entrevista breve para os transtornos mentais. Rev Bras Psiquiatr 2000;22(3):106-15.

24. Andrade L, Walters E, Gentil V, Laurenti R. Prevalence of ICD-10 mental disorders in a catchment area in the city of São Paulo, Brazil. Soc Psychiatr Psychiatr Epidemiol 2002;37(7):316-25.

25. Bromet E, Andrade LH, Hwang I, Sampson NA, Alonso J, De Girolamo G, et al. Cross-national epidemiology of DSM-IV major depressive episode. BMC Med 2011;9:2-16.

26. Molina MRAL, Wiener CD, Branco JC, Jansen K, Souza LDM, Tomasi E, et al. Prevalência de depressão em usuários de unidades de atenção primária. Rev Psiquiatr Clín 2012;39(6):152-4.

27. Serby M, Yu M. Overview: depression in the elderly. Mt Sinai J Med 2003; 70(1):38-44.

28. Djernes JK. Prevalence and predictors of depression in populations of elderly: a review. Acta Psychiatr Scand 2006;113(5):372-87.

29. Barua A, Ghosh MK, Kar N, Basilio MA. Sociodemographic factors of geriatric depression. Indian J Psychol Med 2010;32(2):87-92.

30. Cole MG, Dendukuri N. Risk Factors for depression among elderly community subjects: a systematic review and meta-analysis. Am J Psychiatr 2003; 160(6):1147-56.

31. Weissman MM, Leaf PJ, Bruce ML, Florio L. The epidemiology of dysthymia in five communities: rates, risks, comorbidity, and treatment. Am J Psychiatr 1988;145(7):815-9.

32. Carta MG, Carpiniello B, Kovess V, Porcedda R, Zedda A, Rudas N. Lifetime prevalence of major depression and dysthymia: results of a community survey in Sardinia. Eur Neuropsychopharmacol 1995;5 Suppl:103-7.
33. Fichter MM, Bruce ML, Schröppel H, Meller I, Merikangas K. Cognitive impairment and depression in the oldest old in a German and in US communities. Eur Arch Psychiatr Clin Neurosci 1995;245(6):319-25.

34. Devanand DP. Dysthymic disorder in the elderly population. Int Psychogeriatr 2014;26(1):39-48.

35. Byers AL, Covinsky KE, Barnes DE, Yaffe K. Dysthymia and depression increase risk of dementia and mortality among older veterans. Am J Geriatr Psychiatry 2012;20(8):664-72.

36. Stafford L, Berk M, Jackson HJ. Tobacco smoking predicts depression and poorer quality of life in heart disease. BMC Cardiovasc Disord 2013;13:2-10.

37. Friborg O, Martinsen EW, Martinussen M, Kaiser $\mathrm{S}$, Overgard KT, Rosenvinge JH. Comorbidity of personality disorders in mood disorders: a metaanalytic review of 122 studies from 1988 to 2010. J Affect Disord 2014;152-154:1-11.

38. Holm-Denoma JM, Berlim MT, Fleck MP, Joiner TE Junior. Double depression in adult psychiatric outpatients in Brazil: Distinct from major depression? Psychiatry Res 2006;144(2-3):191-6.

39. Joiner TE Juniorr, Cook JM, Hersen M, Gordon $\mathrm{KH}$. Double depression in older adult psychiatric outpatients: Hopelessness as a defining feature. J Affect Disord 2007;101(1-3):235-8.

40. Klein DN, Schatzberg AF, McCullough JP, Keller MB, Dowling F, Goodman D, et al. Early- versus late-onset dysthymic disorder: comparison in outpatients with superimposed major depressive episodes. J Affect Disord 1999;52:187-96.

41. Dowrick C, Gask L, Perry R, Dixon C, Usherwood T. Do general practitioners' attitudes towards depression predict their clinical behavior? Psychol Med 2000; 30(2):413-9.

42. Carson A, Margolin R. Depression in older patients with neurologic illness: Causes, recognition, management. Clevel Clin J Med 2005;72(3):52-64.

43. Galetti C, Alvarenga PG, Andrade AG, Tavares H. Gambling and substance use bytheelderly: a reviewofthe literature. Rev Psiquiatr Clín 2008;35(Suppl 1):39-43.

44. Irigaray TQ, Schneider RH. Prevalence of depression in elderly women attending the University of Third Age. Rev Psiquiatr Rio Gd Sul 2007;29(1): 19-27. 